\title{
Exploring local fishery management through cooperative acoustic surveys in the Aleutian Islands
}

\author{
Steven J. Barbeaux*, Lowell Fritz, Elizabeth Logerwell \\ Alaska Fisheries Science Center, National Marine Fisheries Service, National Oceanic and Atmospheric Administration, 7600 Sand Point Way NE, Seattle, WA 98115, USA
}

\section{A R T I C L E I N F O}

\section{Keywords:}

Alaska Natives

Aleutian Islands

Cooperative management

Ecosystem-based management

Fishery acoustic survey

Protected species

North Pacific Ocean

Steller sea lion

Walleye pollock

\begin{abstract}
A B S T R A C T
An alternate management system is introduced which uses seasonal and spatially explicit multi-species quotas generated from small-scale cooperative fishery acoustic surveys to manage the Aleutian Islands walleye pollock (Gadus chalcogrammus) fishery while limiting impacts on the endangered Western stock of Steller sea lions (Eumetopias jubatus). This is a novel collaboration among scientists, industry, and Alaska Natives considering a cooperative management approach. The proposed system integrates the catch monitoring and accounting systems already in place in the federal groundfish fisheries off Alaska with cooperative acoustic survey biomass estimates to facilitate more refined spatial and temporal fishery management decisions. Conditions were examined under which such a system could operate successfully and results from field work conducted to assess technical requirements were discussed. During field trials biomass estimates from each survey were produced within 24-h of survey completion. This suggests spatial abundance estimates can be available in a timely manner for managing local fisheries. The proposed management system was found feasible and relatively easy to initiate because of highly motivated and cooperative industry partners, a well-established mechanism for setting allowable catch limits, and a robust catch accounting system already in place. In addition, high quality commercial echosounders required for this system are currently used by industry and, with proper controls on calibration and survey design, produce biomass estimates of sufficient quality. The application of this approach beyond this case study is also discussed for managing fisheries worldwide where fine temporal and spatial scale management could benefit the conservation of other protected species.
\end{abstract}

\section{Background}

In 2004 the Aleutian Islands (AI) walleye pollock (Gadus chalcogrammus; hereafter pollock) quota for the AI area was allocated to the Aleut Corporation through an amendment to the Magnuson-Stevens Fishery Management Act (MSA) [1]. Under the Alaska Native Claims Settlement Act of 1971 (US Public Law 92-203) the Aleut Corporation (see www.aleutcorp.com) was created to represent the interests of the native Aleuts and their descendants and pursues beneficial economic and cultural projects in the region. The allocation of pollock was meant as a means to spur development of a commercial fishery based on Adak Island to take advantage of the infrastructure at the decommissioned Adak Naval Station. During World War II the Aleut people were relocated from the Western and Central AI to camps in Southeastern Alaska. Although Aleuts were allowed to return to some of the islands after the war, Adak Island remained under United States military control until 1997. Resettlement of Adak did not began until 1998 when the Island and accompanying infrastructure was acquired by the Aleut
Corporation from the United States Navy and United States Department of Interior in exchange for other lands in the region held by the corporation.

In 2005 the Aleut Corporation allowed two catcher-processor trawl vessels to fish the AI pollock allocation. However, the 2005 AI pollock fishery was a failure with only $109 \mathrm{t}$ of the $15,500 \mathrm{t}$ allocated quota being harvested by the directed fishery. The failure of the fishery was mainly due to the majority of pollock habitat in the AI area near Adak Island being closed to pollock fishing (Fig. 1).

The North Pacific Fishery Management Council (NPFMC) imposed spatial restrictions on the pollock fishery in the AI to protect potential prey fields for the endangered western stock of Steller sea lions (Eumetopias jubatus; hereafter W-SSL). The entire SSL population (eastern Russia, across Alaska, and south along the coast of North America to central California) declined by 75\% between 1976 and 1990, and in 1990 was listed as threatened range-wide under the Endangered Species Act of 1973 (US Public Law 93-205; hereafter ESA). In 1997, NMFS recognized eastern (California north through

\footnotetext{
* Corresponding author.

E-mail address: steve.barbeaux@noaa.gov (S.J. Barbeaux).
} 


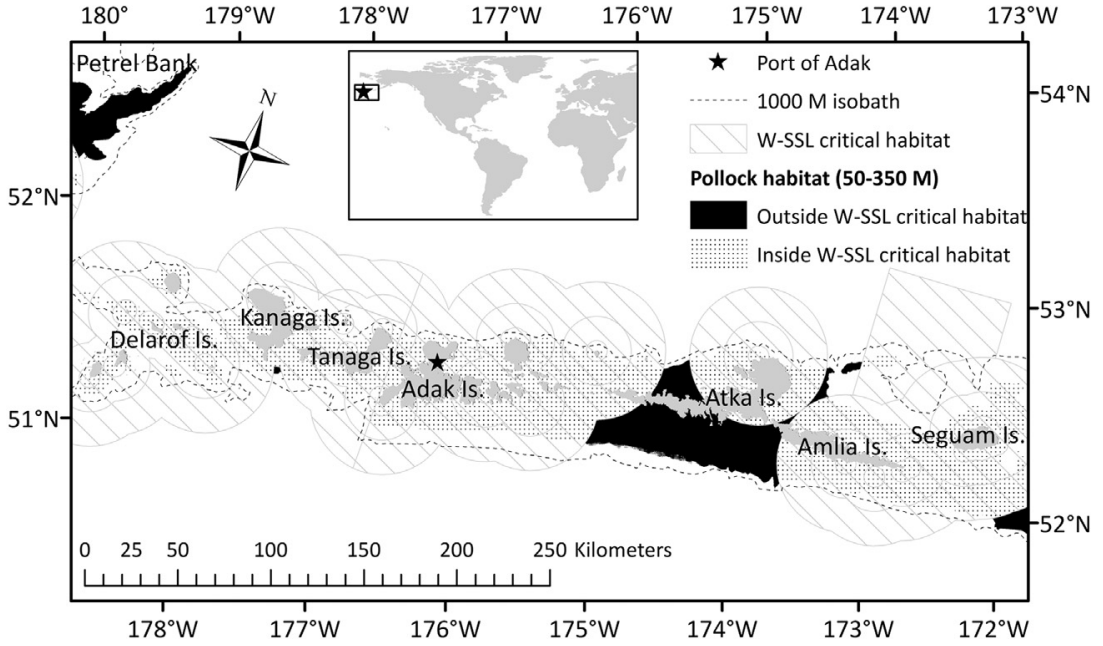

Fig. 1. Map of the central Aleutian Islands showing designated Western stock of Steller sea lion (W-SSL) critical habitat (hatched) and pollock habitat inside (stippled) and outside (black) of W-SSL critical habitat in 2005. Inside W-SSL critical habitat was the area closed to fishing in 1999. southeastern Alaska) and western stocks (Russia and central/western Alaska) based on genetics, morphology, and differences in population trend. The ESA status of the eastern stock remained threatened (it has since recovered and was removed from ESA protection in 2013), while the status of the western stock was changed to endangered due to persistent declines: between 1991 and 2000 the stock declined another $40 \%$ [2]. While the overall decline of the W-SSL in Alaska stopped in the early 2000s and populations in the Gulf of Alaska and eastern Bering Sea have increased at $\sim 3 \% \mathrm{y}^{-1}$ through 2016, populations throughout much of the Aleutian Islands continue to decline and the $\mathrm{W}$ SSL population overall is not meeting recovery goals set by the management agency [3]. It is likely that the cause(s) of the initial overall decline are different from those that are inhibiting recovery $[2,4,5]$. The initial decline prior to ESA listing in 1990 was likely driven by a combination of direct mortality from incidental take in fisheries and both legal and illegal shooting [4,5]. It has also been hypothesized that indirect mortality resulted from nutritional stress related to climate and environmental (e.g. regime shifts) changes and fisheries competition $[2,4,5]$. The sources of direct mortality were largely controlled following ESA listing [2], yet the W-SSL continued to decline overall for at least another decade or more, and continues to decline throughout much of the AI [6]. As a result, research and management attention has focused on indirect factors that would have more subtle effects on WSSL reproduction and survival, such as nutritional stress and contaminants [7].

In the United States, the Marine Mammal Protection Act of 1972 (MMPA; US Public Law 92-522) and ESA require federal fisheries managers to consider possible fishery interactions with protected species when developing fishery management plans (FMP). Interactions include both direct takes of the protected species and secondary effects due to the removal or dispersal of prey. AI pollock had been identified as a primary winter prey species for the W-SSL and the NPFMC has regulated the spatial and temporal distribution of the pollock fishery in an attempt to limit competition with W-SSL. In 1998 the NPFMC closed the entire AI management area to directed pollock fishing. In 2005, to allow a pollock fishery by the Aleut Corporation, the NPFMC opened all waters outside of W-SSL critical habitat in the AI to directed pollock fishing. The total area of suitable pollock habitat (defined here as $50 \mathrm{~m}$ and $350 \mathrm{~m}$ bottom depth) within $250 \mathrm{~km}$ of the port of Adak was approximately $14,750 \mathrm{~km}^{2}$, of this $3416 \mathrm{~km}^{2}$ was outside of W-SSL critical habitat and opened to directed pollock fishing (Fig. 1).

Another complicating factor limiting the AI pollock fishery is that pollock and Pacific ocean perch (Sebastes alutus; hereafter POP) occupy similar habitat in the AI. In 2005 POP bycatch exceeded 50\% in the directed AI pollock fishery [8]. In this document bycatch is defined using the definition posited in the Magnuson-Stevens Fishery
Conservation Act; bycatch is fish that are harvested in a fishery but which are not sold or kept for personal use. In the AI POP are subject to their own directed fishery, but more importantly, they are bycatch in more valuable fisheries such as Atka mackerel (Pleurogrammus monopterygius) and Pacific cod (Gadus macrocephalus). The AI POP bycatch quota is set for all non-directed fisheries and 2005 AI pollock fishery was halted by the fishing industry because, if sustained, the POP bycatch levels in the pollock fishery would have threatened to close other fisheries. It was apparent that under the 2005 management framework a successful AI pollock fishery was not possible given the small area of pollock habitat available to the fishers and high levels of POP bycatch encountered outside of W-SSL critical habitat.

\section{Real-time local cooperative management}

After the 2005 fishing season, scientists with the National Marine Fisheries Service (NMFS) Alaska Fisheries Science Center (AFSC) began working with the Aleut Corporation, local fish processors, and fishers to explore alternative management systems that would provide for an AI pollock fishery, but continue to protect W-SSL. Industry stakeholders wished to conduct the AI pollock fishery in mid-to late-March, when pollock value would be at its peak due to roe content. In 2005 roe wholesale value was $\sim \$ 13,500$ per ton, while whole pollock wholesale value was $\sim \$ 782$ per ton [9]. The Pacific cod fishery was usually closed at this time of year and a March pollock fishery would allow fishers to participate in both the pollock and Pacific cod fisheries.

One of these alternate management systems was introduced which uses seasonal and spatially explicit multi-species quotas generated from small-scale cooperative fishery acoustic surveys [10] to manage the fishery. Fishery acoustic surveys are standardized fish surveys which employ echosounders that use active sound to enumerate fish abundance [11]. If adopted, this management approach would be administered as a sub-allocation subject to all other quotas and limits already in place for the region-wide AI fisheries, except allowing a limited midwater fishery within W-SSL critical habitat. The surveys would be conducted by the commercial fishers, certified by AFSC acousticians, and a multi-species, overall biomass limit would be set for the surveyed area prior to the fishery opening. This management system was thought possible because 1) there is a well-established mechanism for setting allowable catch limits [12], 2) a robust catch accounting system in place [13], and 3) the commercial echosounders used by fishers and the scientific echosounders used by the AFSC to survey pollock are produced by the same company and the echosounder hardware is nearly identical. Data from the commercial and scientific echosounders have been shown to be comparable when the echosounders are properly calibrated and data properly processed [14]. 


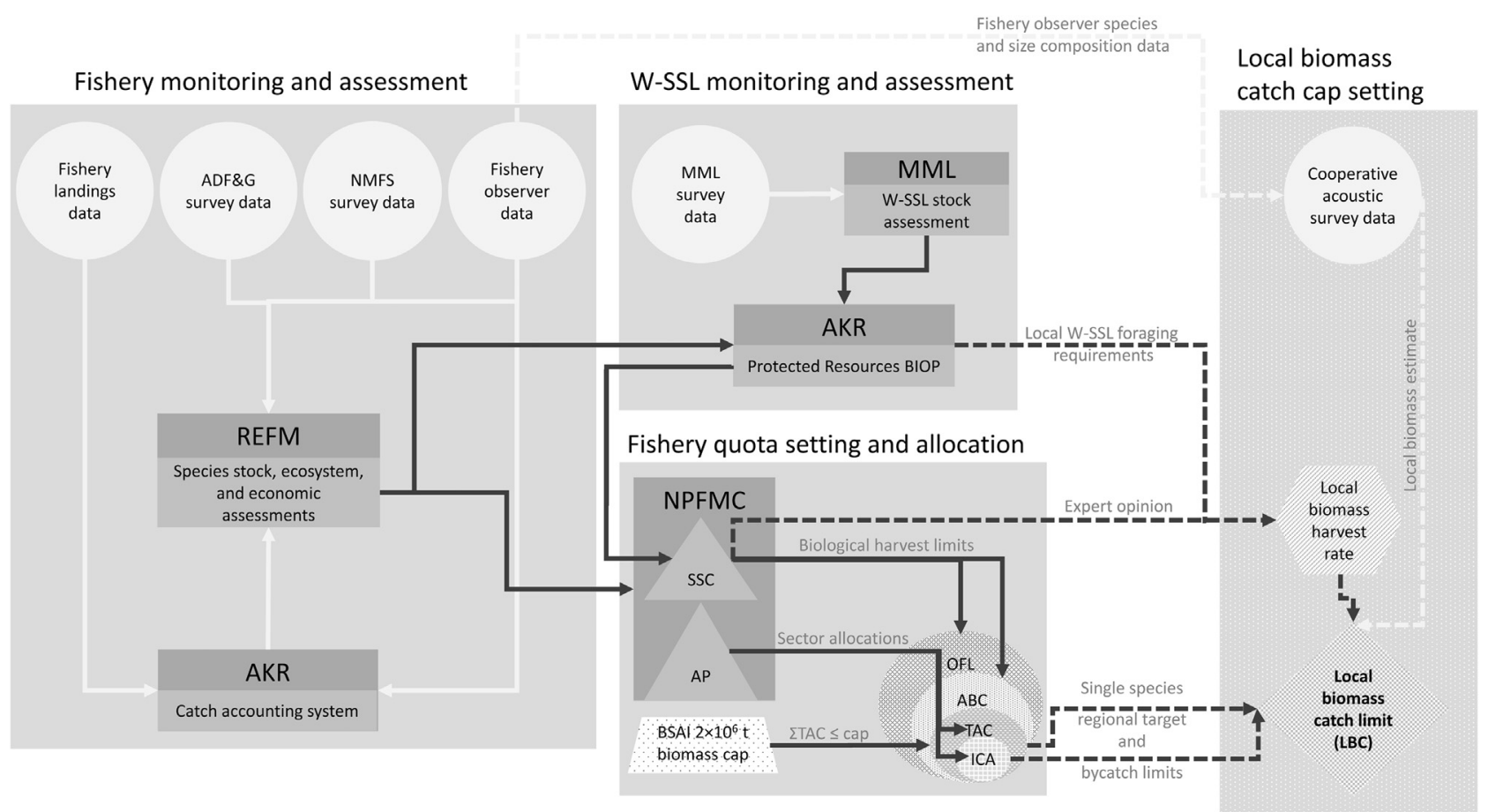

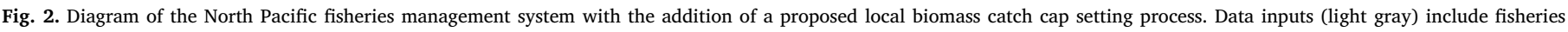

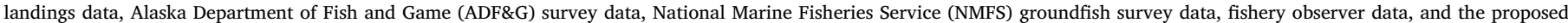

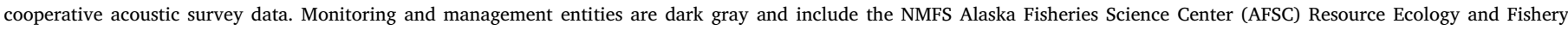

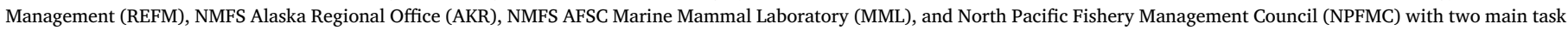

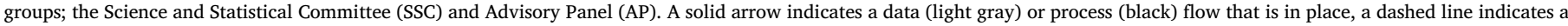

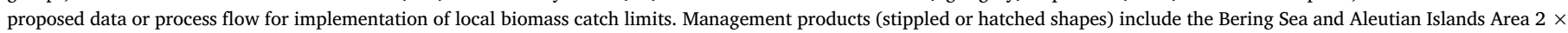

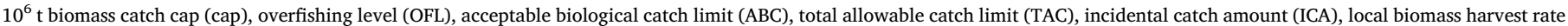
limit, and the local biomass catch limit (LBC).

The proposed cooperative fisheries management system would rely on the integration of the catch monitoring and accounting systems already in place in the federal groundfish fisheries off Alaska [12,13] with local cooperative acoustic survey biomass estimates (Fig. 2). The federal groundfish fisheries off Alaska have a well-established observer program in which contracted biologists ("observers") work on board fishing vessels to document catch and catch composition [15]. These data are transmitted via satellite on a daily basis and integrated into a catch accounting system. The North Pacific catch accounting system uses observer data in combination with fisher-reported landings data to estimate total catch for each species and gear type. These estimates are used to affect timely in-season management actions when previously determined catch limits have been reached, including area and specieswide closures. The total allowable catch (TAC) limits and the incidental catch amount (ICA), a portion of the TAC set aside for bycatch, for each species, region, and fishing sector are determined on an annual basis. This is achieved through a combination of stock assessment modeling and scientific deliberation to set biological limits and negotiations among fishing sector representatives to allocate the available catch among fishing sectors. As required by the MSA, the NPFMC Science and Statistical Committee (SSC) sets acceptable biological catch (ABC) and overfishing limits (OFL) at a regional and species level based on the best scientific advice from AFSC annual single-species stock assessments, ecosystem assessment, and economic assessment [8]. For every managed groundfish species the NPFMC Advisory Panel (AP) made up of industry representatives recommends an annual or seasonal TAC for each fishing sector which in sum cannot exceed the $A B C$ for each species and region, and for the Bering Sea and AI region, cannot exceed 2 million tons for all federally managed groundfish species in total. Although not a strict requirement, the NPFMC generally accepts the recommendations of the SSC for setting OFL and ABC and the AP for setting TACs and ICAs.
The cooperative management system proposed would retain seasonal AI TACs and ICAs for each groundfish species and in addition implement time-sensitive local biomass catch (LBC) caps. The LBC would be a proportion of the overall mid-water biomass estimate from cooperative acoustic surveys. The harvest percentage would be determined by the SSC based on the estimated maximum local biomass harvest rate, or threshold, or both that is, in the opinion of the SSC in consultation with NMFS Alaska Regional Office Protected Resource Division (PR), below the level that would adversely impact W-SSL foraging success and therefore would not likely jeopardize the continued existence of W-SSL. Under this management system the fishery would close when: 1) the LBC was reached in the managed sub-area, 2) the TAC or ICA for any individual fish species was reached for the region and sector, or 3) a set time period following the certification of the official cooperative acoustic survey determined by the SSC which takes into account the ephemeral nature of mid-water and near-bottom fish aggregations in the $\mathrm{AI}$ in the late winter and early spring.

In the proposed management system the Aleut Corporation would determine the spatial extent of the sub-area and timing of the cooperative acoustic survey, request the NPFMC to determine the LBC harvest rate, and notify NMFS which vessels are to be eligible to participate in the fishery. NMFS would approve the sub-area and design the acoustic survey. The NPFMC in consultation with the NMFS PR would set the sub-area LBC rate. The Aleut Corporation would conduct the acoustic survey with limited pelagic verification trawls (less than $100 \mathrm{t}$ ) to identify species and size composition and process the acoustic survey data to obtain an overall biomass estimate for the sub-area. NMFS would review and certify the survey and biomass estimates and set the official sub-area LBC based on the SSC determined allowable local biomass harvest rate and cooperative survey biomass estimate. Catch would be monitored through on-board observer collected data and landings reports to ensure catch remained under the LBC and regional 
TACs and ICAs for all species. All vessels would be required to carry a fisheries observer, all catch would be retained until weighed on a certified scale, and fishing gear would be limited to pelagic trawl gear as previously defined for pollock fisheries in the Bering Sea and Aleutian Islands Area (50 C.F.R. § 679.2).

For such a cooperative management system to succeed: 1) commercial fishing vessels employed by the Aleut Corporation must be able to collect appropriate quality acoustic data during late February to late March when high winds and rough sea states prevail, 2) mid-water and near bottom fish biomass in proposed fishing zones must remain stable for the duration of the fishery or seasonal fluctuations in biomass be understood, 3) there must be a method for determining a harvest rate that accounts for the foraging requirements of local W-SSL populations and allows for their recovery under the U.S. Endangered Species Act, and 4) the costs of cooperative surveys would need to be less than potential profits from the fishery. To test the technical aspects of the proposed management system cooperative acoustic surveys were conducted in the late winter and early spring of 2006, 2007, and 2008.

\section{Aleutian Islands Cooperative Acoustic Survey Studies (AICASS)}

\subsection{AICASS 2006}

The first exploratory Aleutian Islands cooperative acoustic study (AICASS) was conducted in 2006 [14] and had three main objectives:

1) to explore the distribution of mid-water and near bottom fish in the central Aleutians Islands in an area accessible to catcher vessels delivering to Adak Island,

2) to investigate the spatial distribution of fish aggregations in the area to determine optimum transect spacing for future surveys, and

3) to evaluate the quality of acoustic data from and the noise characteristics of the commercial fishing vessel used in the survey.

The Aleut Corporation agreed to allocate $1000 \mathrm{t}$ of AI pollock quota for the study and, through an exempted fishing permit approved by NMFS (50 CFR 679.6; hereafter EFP), fishers involved in the study were allowed to harvest up to $1000 \mathrm{t}$ of groundfish in the study area including within W-SSL critical habitat. The FV Muir Milach, a $23 \mathrm{~m}$ stern trawler (Fig. 3), was selected by the Aleut Corporation to conduct the study and fish between survey efforts in the study area to offset costs of the survey. Methods employed to collect and process the data have been described previously [14]. Eight separate surveys were conducted between 5 March and 5 April in an area north of the AI chain between $174.3^{\circ} \mathrm{W}$ and $175.3^{\circ} \mathrm{W}$ longitude identified by the fishers as an area of high pollock abundance (Fig. 4). The largest extent of the area surveyed in 2006 was 180 square nautical miles $\left(\mathrm{NM}^{2} ; 618 \mathrm{~km}^{2}\right)$. The biomass of pollock in this area at the start of the study was considered high with a density of $60.36 \mathrm{t} \mathrm{NM}^{-2}\left(17.58 \mathrm{t} \mathrm{km}^{-2}\right)$ for a total of $10,865 \mathrm{t}$, but decreased substantially in 22 days during the study to only $21.33 \mathrm{t} \mathrm{NM}^{-2}$ $\left(6.21 \mathrm{t} \mathrm{km}^{-2}\right)$ for a total of $3839 \mathrm{t}$ [16]. This was a drop of $7026 \mathrm{t}(65 \%$ of the initial survey) even though only $965 \mathrm{t}$ were removed by the survey and commercial fishery during the study period, thus the decrease in biomass was largely due to fish moving out of the survey area. Fish other than pollock comprised less than 1\% of the mid-water and near-bottom biomass intercepted by the trawl in the study area. All catch was retained and delivered to the processor on Adak Island prior to starting each new survey. Landings data including weight and species composition were transmitted within $24 \mathrm{~h}$ and entered into the NMFS Alaska Regional Office catch accounting system [14].

Although the 2006 study revealed that fish aggregations in the surveyed area were spatially and temporally dynamic at small scales, the study established that conducting acoustic surveys in the $\mathrm{AI}$ in the late winter and early spring from a commercial fishing vessel was possible and that data were of adequate quality to make reasonably precise biomass estimates [14]. At the conclusion of the 2006 study the fishing vessel captain, the Adak Fisheries plant manager, the Aleut Corporation executive manager, and the NMFS AFSC lead researcher (Barbeaux) were informally interviewed to determine each stakeholder's perception of the project, provide an avenue for suggesting improvements, and assess whether the project should be continued. All of the participants responded that the project, in their view, was a success meeting all of the objectives for which they participated in the project, and that future work in this area should be continued [14]. One problem identified was a lack of lead time for the fishers who participated in the project. The lead NMFS AFSC researcher worked solely with the processing plant operator and Aleut Corporation executive manager in project planning, fishers were notified of the project only a few weeks before the study was conducted and had little input prior to the study on design or implementation. This lack of coordination lead to delays as equipment necessary for the survey was not on the vessel and stored in Dutch Harbor, Alaska, 443 NM $(820 \mathrm{~km})$ distant. Fishers also identified several issues with the study area selection that required some initial changes to the planned survey area. Fishers had a more current understanding of fish distribution and the initial study area contained a number of fishing hazards that were not shown on navigation charts. The delays, although not critical to the project success, could have been avoided had the project involved the fishers much earlier in the design phase.

\subsection{AICASS 2007}

Taking into consideration the lessons of the 2006 study, the 2007 study was designed in consultation with representatives for stakeholders and three pre-study meetings were held [17]. Through these meetings the area of the survey was expanded to the full area of interest for fishers participating in the AI pollock fishery and the startup delays encountered in 2006 were avoided. The expanded study area included waters north of the islands between $172^{\circ} \mathrm{W}$ and $179^{\circ} \mathrm{W}$ longitude comprising a $1595 \mathrm{NM}^{2}\left(5477 \mathrm{~km}^{2}\right)$ survey area [10] (Fig. 4). The objectives of the 2007 study were to

1) obtain biomass estimates for the expanded study area,

2) determine if the distribution of fish in the study area was consistent

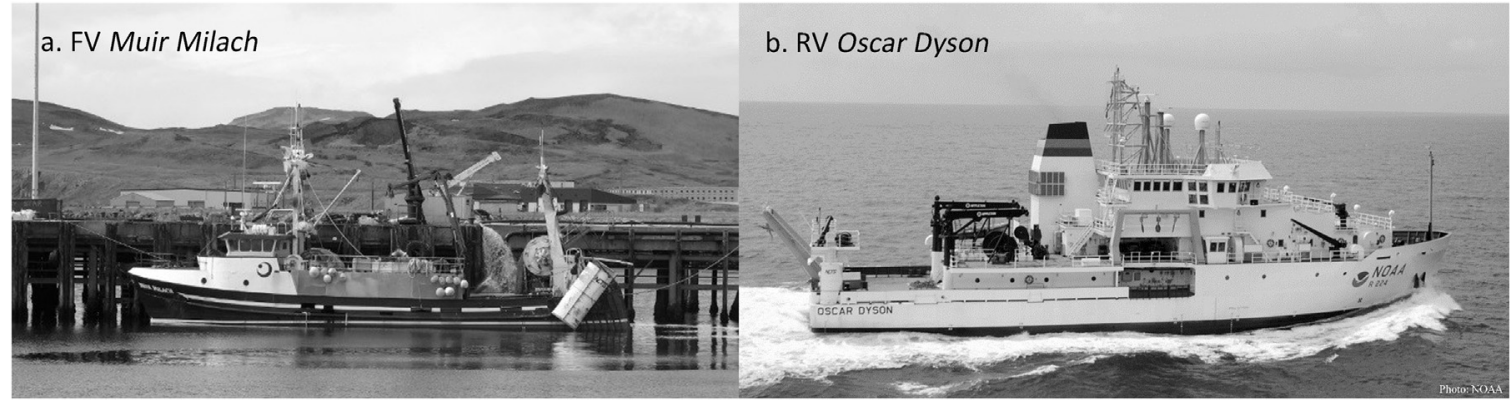

Fig. 3. (a) The $23 \mathrm{~m}$ stern trawler FV Muir Milach used as the cooperative acoustic survey vessel and (b) the $64 \mathrm{~m}$ NOAA ship RV Oscar Dyson. 


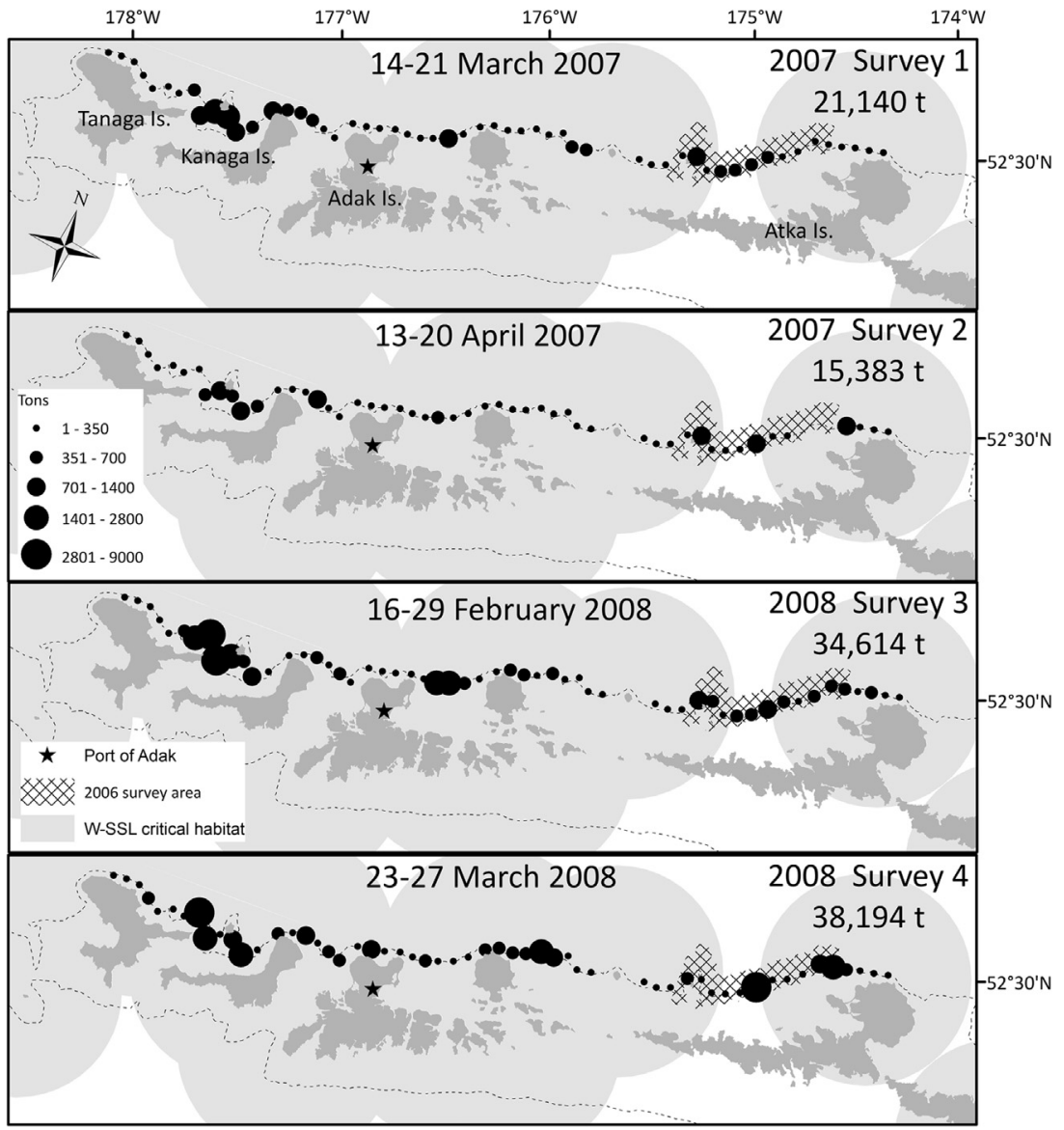

Fig. 4. Mid-water and near bottom biomass and distribution for the 2007 and 2008 AICASS. Points represent the starting point and sum in tons of the overall mid-water and near bottom $(0.5 \mathrm{~m}$ from bottom to $15 \mathrm{~m}$ from surface) biomass of Pacific ocean perch and pollock for each transect [16].

over time, and

3) assess the stability of the fish biomass in the study area to evaluate the temporal relevance of a local biomass catch limit.

Two 7-day surveys were planned for mid-March and mid-April with a commercial fishery between the two surveys. The Aleut Corporation allocated $3000 \mathrm{t}$ of pollock for the study from their 19,000 t AI pollock allocation. The 2007 study was again conducted under an EFP with the fishery allowed to harvest up to $3000 \mathrm{t}$ of groundfish from the study area. Geostatistical simulations developed using data on fish distribution and vessel survey speeds collected in 2006 [17] demonstrated that at a $2.5 \mathrm{NM}(4.6 \mathrm{~km})$ inter-transect spacing the expanded study area could be surveyed in 7 days with a relative estimation error $[18,19]$ of less than 0.2 (Fig. 5). The Muir Milach was again selected as the acoustic

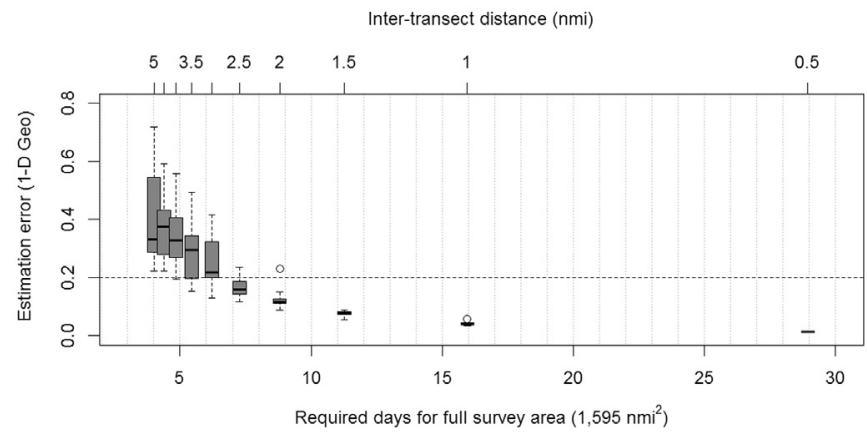

Fig. 5. Simulated relative estimation error generated from a 1-D geostatistical estimator [18] by transect distance and estimated costs in number of 16-h days from a simulation of mid-water and near bottom fish distribution in the Central Aleutian Islands generated from the spatial relationships of fish distributions and vessel survey speeds observed in the 2006 Aleutian Islands Cooperative Acoustic Survey Study [16]. survey vessel, however an additional trawl vessel, the $37 \mathrm{~m}$ stern trawler FV Intrepid Explorer, was added to conduct verification trawls in an effort to speed the acoustic survey. Two stern trawlers (FV Bristol Explorer and FV Northwest Explorer) were also added to the study design and expected to commercial fish the $3000 \mathrm{t}$ survey allocation between surveys to help offset survey costs. None of the new fishery participants were included in the initial planning phase of the study and had little introduction to the study design and objectives.

The first 2007 acoustic survey was successfully conducted on the 14-21 of March over seven active survey days, realizing the predictions of the simulation study. The survey was conducted as a series of parallel transects running north-south, approximately perpendicular to the shelf break with an initial random start location. The survey resulted in an estimate of $13.23 \mathrm{t} \mathrm{NM}^{-2}\left(3.86 \mathrm{t} \mathrm{km}^{-2}\right)$ with a total biomass of $21,140 \mathrm{t}$ (relative estimation error of 0.09) for the expanded study area (Fig. 4). Pollock were estimated to comprise $91 \%$ and POP $9 \%$ of the mid-water and near bottom biomass. The low density encountered was similar to the density estimated for the final 2006 survey.

The second 2007 survey was completed on 15-20 April following the same transects as the first survey, however the duration of the second survey was reduced to 5 days by stopping the acoustic survey data collection on transects when there were no longer fish observed. This survey resulted in a lower density of pollock at $9.64 \mathrm{t} \mathrm{NM}^{-2}$ $\left(2.81 \mathrm{t} \mathrm{km}^{-2}\right)$ with an overall decrease in mid-water and near-bottom biomass from the first survey of $5757 \mathrm{t}$ (27\% decrease) to $15,383 \mathrm{t}$ and an increase in relative estimation error to 0.13 (Fig. 5). Between surveys $1327 \mathrm{t}$ of fish were removed by the survey and commercial fishery during the study period, thus the difference in biomass between surveys was within the bounds of the survey relative estimation error of 0.2 . For the second 2007 survey pollock made up $90 \%$ of the mid-water and near-bottom biomass while POP made up most of the remainder.

Adding the additional survey vessel to conduct verification trawls 
did not increase the efficiency of the survey. The mid-water trawl net used by Muir Milach had been specifically tailored for fishing in the high relief and rocky conditions of the AI. The mid-water net used by the Intrepid Explorer had been designed to fish pollock on the gently sloping and primarily muddy bottom of the eastern Bering Sea shelf and was more than twice the width of the net used by the Muir Milach, making it much less maneuverable. The fishing captain also had less experience fishing pollock in the AI than the captain of the Muir Milach. A midwater net used by the Intrepid Explorer was destroyed (a $\sim \$ 100,000$ loss) on the first verification trawl when it struck a pinnacle, leaving the vessel with only one mid-water net for the remainder of the survey. For each verification trawl afterwards the Intrepid Explorer inspected all targeted fishing zones extensively prior to deploying their net, greatly increasing the amount of time necessary to conduct the verification trawls and eliminating any efficiencies that would have been gained by using a second vessel.

The paired commercial fishery was considered a failure by the nonNMFS stakeholders. Only $1170 \mathrm{t}$ of pollock was harvested, less than half of the $3000 \mathrm{t}$ allocation. At 2013 ex-vessel values the pollock catch would have grossed approximately $\$ 915,000$ US. However, because the processing plant had problems marketing the catch, revenue from the fishery was substantially lower [20]. Operating costs for the vessels involved including crew costs for the survey and fishery was estimated at approximately $\$ 575,000$, not including the loss of the large midwater net. The plant had net negative revenue for this fishery and the fishers netted considerably less than they could have in the Bering Sea Pacific cod fishery which opened 1 April. It should be noted that the low amount of catch was not solely due to lower than expected fish abundance. The two commercial fishing vessels (FV Bristol Explorer and FV Northwest Explorer) that had been selected to fish between surveys did not participate: one because of mechanical problems and the other because the financial risks of participating in the survey were deemed too great. In addition, on the morning of 18 March a sister ship of the Intrepid Explorer ran aground and sank near the Port of Adak. The Intrepid Explorer ceased all survey efforts and commercial fishing to aid in the recovery. This left the Muir Milach to conduct the remainder of the commercial fishery and verification trawls in the second survey. There was insufficient time for the Muir Milach to fish the remainder of the allocation by itself as the captain chose to participate in the more lucrative eastern Bering Sea Pacific cod fishery before that fishery closed.

From a technical fisheries management perspective the study was a success. Biomass estimates for each survey were produced within 24-h of survey completion and therefore estimates would have been available in a timely manner for managing a local fishery. Data quality remained adequate for survey estimates with a $4.2 \%$ missing sample rate across both surveys [14]. Missing samples were primarily due to air bubble interference on the transducer face during rough sea states causing the acoustic pings (samples) to be at an unacceptably low signal strength. The NMFS catch accounting system performed as designed with observer and landings data reported to the NMFS Alaska Regional Office within 24-h of landing. All catch by species was fully tallied by the last day of the study and no regional or area-specific limits were exceeded.

\subsection{AICASS 2008}

Although a 2008 study had been planned, in consideration of the 2007 fishery failure there was little interest by the fishers or the Aleut Corporation in continuing the project without external monetary compensation. A research proposal to conduct the project in 2008 was successfully funded through a North Pacific Research Board grant (NPRB; Project 730). The funded project involved two fishery acoustic surveys of the same expanded study area surveyed in 2007, one by a $64 \mathrm{~m}$ state-of-the-art noise-quieted acoustic research vessel, NOAA ship Oscar Dyson (Fig. 3) and a second by the Muir Milach [16,21]. In addition to the acoustic surveys, concurrent W-SSL diet and population abundance surveys were also funded for the study area (NMFS MMPA Research Permit 782-1889). The objectives of the 2008 study were to

1) assess the abundance and distribution of mid-water and near-bottom fish in the study area,

2) determine distribution and age and sex composition of the W-SSL population in the study area,

3) evaluate possible prey fields for W-SSL and the proximity of prey to W-SSL haulouts in the area, and

4) describe the diets of W-SSL in the study area. The fishery acoustic surveys were conducted under a NMFS Scientific Research Permit. A concurrent fishery was not planned and no pollock were allocated by the Aleut Corporation.

The two acoustic surveys in 2008 followed the same transects as the 2007 study [15]. The first survey conducted by the Oscar Dyson took 15 days between 16 and 29 February and found mid-water and nearbottom fish density higher than previous surveys at $21.7 \mathrm{t} \mathrm{NM}^{-2}$ $\left(6.3 \mathrm{t} \mathrm{km}^{-2}\right)$ and an estimated biomass of 34,614 the proportion of the biomass comprised of pollock dropped from the previous year's study to $78.4 \%$ with POP primarily making up the difference. The second acoustic survey conducted by the Muir Milach was completed in 5 days between 23 and 27 March. Estimated fish density in the second survey was $23.95 \mathrm{t} \mathrm{NM}^{-2}\left(6.98 \mathrm{t} \mathrm{km}^{-2}\right)$ for a total of $38,198 \mathrm{t}$. The apparent increase of $3580 \mathrm{t}$ was within the margin of error for the two surveys conducted in 2008 [16]. The proportion of the biomass comprised of pollock was similar to the earlier 2008 study at $76.4 \%$. No commercial fishing of mid-water and near-bottom species was conducted in the study area during or between the two surveys.

Although the Oscar Dyson was able to collect acoustic data at faster vessel speeds than the Muir Milach (11 knots vs. 7 knots on average) the actual survey duration for the Oscar Dyson was three times as long for the same survey area (15 days vs. 5) and daily costs of ship operations were more than double ( $\$ 15,000$ vs. $\$ 6857$ ). The estimated Oscar Dyson operational cost (e.g. fuel and supplies) for the initial 2008 survey, including survey, port, and transit time (17 days), was $\$ 255,000$. The contract costs for the second survey conducted by the Muir Milach was $\$ 68,570$ for 10 days including port, calibration, survey, and transit days. The additional time taken for the Oscar Dyson survey was due to a slower net deployment and retrieval for verification trawls and because the captain of the Oscar Dyson ceased survey operations at much lower sea states than the captain of the Muir Milach.

The Oscar Dyson was built for acoustic survey work but was not well suited for conditions experienced during this survey. Even moderate wind conditions $(20-25$ knots) created difficulty in conducting verification trawls on board the larger research vessel as the tall and broad superstructure required the vessel to fish into the wind. Survey operations were often halted due to crew safety concerns because of pitch and roll at wind speeds greater than 30 knots. Due to the fishers' long experience in heavy weather and better design of the Muir Milach for fishing in the AI, verification trawls were efficiently cast and retrieved even under very rough conditions and survey operations continued even in wind speeds exceeding 50 knots.

When compared with the Muir Milach acoustic data, the acoustic data collected by the Oscar Dyson was much better quality overall with less noise and fewer missing samples. Although the acoustic transducers on both vessels were similarly stable over time, during the surveys the dedicated acoustic research vessel had only a $0.1 \%$ loss of acoustic samples while the fishing vessel had a $4.5 \%$ loss of acoustic samples [21] due to poor data quality. In neither case was the sample loss thought to substantially impact survey results as it was intermittent and not persistent for any individual transect. Although not essential for the AICASS, the Oscar Dyson had the ability to collect data over multiple acoustic frequencies, to collect substantially more types of oceanographic data during the survey, and accommodations on board the research vessel were far more comfortable. 


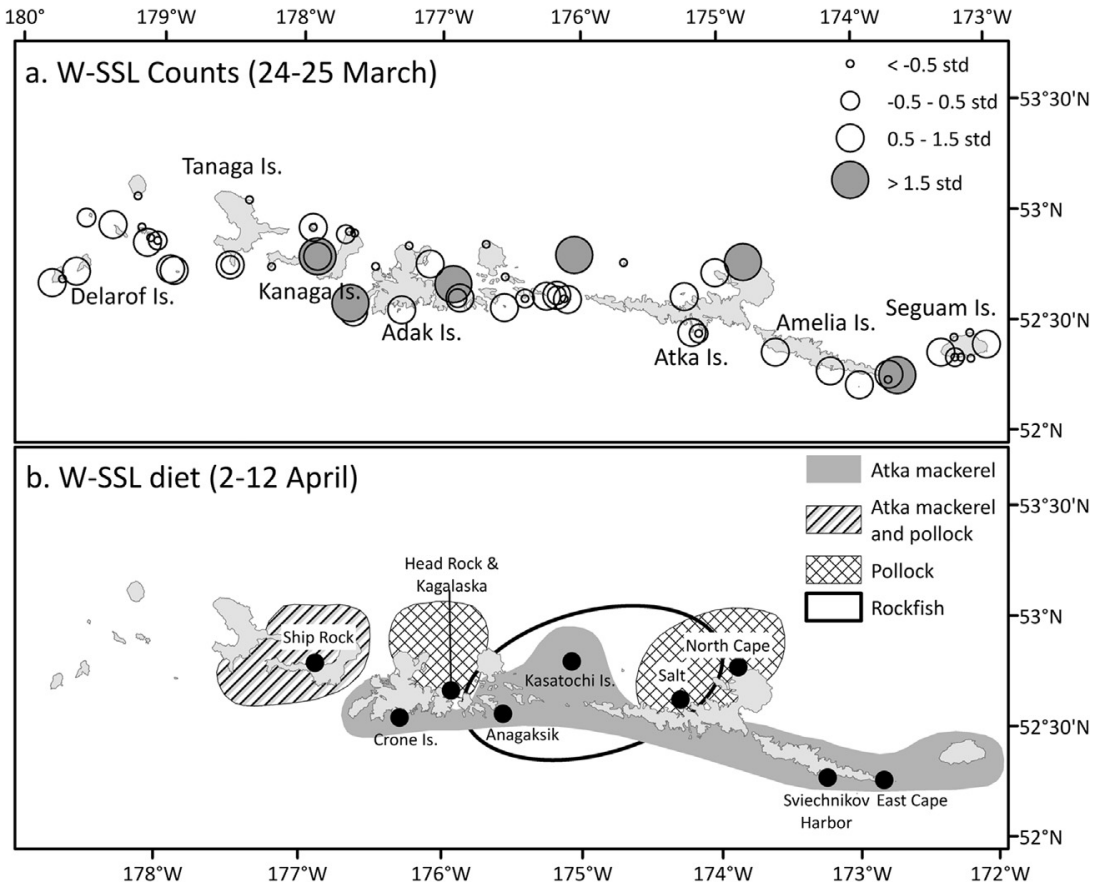

Fig. 6. (a) Western stock of Steller sea lion (W-SSL) counts. Mean number of adult and juveniles during Pass 1 (24-25 March), scaled by 0.5 standard deviation units \pm the mean count at all sites (mean $=$ 55; std. dev. $=70$ ) (b) W-SSL diet. Points represent collection sites and shading represents primary species grouping in the SSL diet data from a principle components analysis [21].

\subsection{Sea lion abundance and diet 2008}

The W-SSL survey was conducted using aerial photography taken from a NOAA Aircraft Operations Center Twin Otter aircraft (N56RF) flying at an average altitude of 750 feet $(228.6 \mathrm{~m})$ and a speed of $90 \mathrm{kts}$ over haulout sites in the Central AI [21]. Two replicate surveys were attempted. The first on 24-25 March surveyed all 59 known W-SSL sites (Fig. 6), while the second 26-29 March) only surveyed 39 sites because of poor weather conditions. The average total count for the complete survey was 3236 sea lions with site totals ranging from 0 to 372 animals. The average total number of animals counted in the second incomplete survey was 2169. The average count at these same sites during the first survey was 2086, a difference of less than 4\% [20]. These are not population estimates since the counts did not account for animals at sea during the survey.

For the W-SSL diet survey from 3 to 9 April 2008, researchers deployed a skiff from the $33 \mathrm{~m}$ RV Norseman onto 10 haulout sites within the study area collecting a total of 301 scat (fecal) and 5 spew samples [21]. It should be noted that scat and spew samples may not reflect diet on long-duration foraging trips, but rather reflect portions of the trips that occurred within the fished areas. From these specimens a total of 41 different species or groups of prey were identified, with the most common being Atka mackerel (Pleurogrammus monopterygius; 53\% overall frequency of occurrence [FO]), a rockfish species (most likely northern rockfish Sebastes polyspinus [21]; 30\% FO), Pacific cod (26\% FO), and pollock ( $26 \% \mathrm{FO})$. The diet data showed that W-SSL were opportunistic feeders on prey that was locally abundant near the scat collection haulout sites. Those sites with high pollock and rockfish were near areas where substantial pollock or rockfish were observed in the fisheries acoustic surveys. Overall, Atka mackerel (27\%), Pacific cod (24\%), sculpins (12\%), smooth lumpsuckers (11\%), and rockfish (5\%) provided the majority of the energy consumed by W-SSL in the Aleutian Islands during the March-April period sampled in 2008 and a subsequent study in 2012, while pollock provided only $2 \%$ [21]. Atka mackerel, which lack a swim bladder, and Pacific cod, which tend to be closely associated with the bottom, cannot be surveyed acoustically and therefore overall abundance of these species was not known [16].

\section{Discussion}

\subsection{Implications for the Aleutian Islands pollock fishery}

The 2006-2008 AICASS demonstrated that using cooperative acoustic surveys to manage the AI pollock fishery while reducing impacts on W-SSL is technically feasible $[14,16,17]$. However, the technical feasibility of conducting the surveys and adapting the catch accounting system to accommodate the proposed management system has proven to be simpler than the far more complex economic and social issues surrounding the fishery and its impacts on the endangered WSSL.

Determining the proportion of fish to allocate as forage for the local W-SSL population recovery is a complex issue that includes both biological and social aspects. Under the ESA determining allowable levels of fishing within W-SSL critical habitat requires an assessment of the impact of proposed fishing levels to determine whether the action will adversely affect the endangered species. That fishing has an impact on the environment is not disputable as fish are removed from the system. The threshold of when fishing impacts are insignificant or discountable as well as the level of uncertainty around this threshold is the nexus of the debate. While considerable effort has been expended to understand the seasonal nutritional requirements for individual W-SSLs [22-24], less is known about the size of local, seasonal prey populations required to support the recovery of W-SSL populations. For instance, the abundance of pollock, Pacific cod, Atka mackerel, and other prey necessary for central Aleutian Islands W-SSLs during the winter and early spring $[25,26]$ is not simply limited to the fish they consume, but also includes the much larger number of fish necessary in the environment to guarantee successful foraging [27-29]. Womble et al. [27] and Sigler et al. [29] concluded that the relationship between Steller sea lion abundance at seasonal haulouts and local prey biomass (e.g. temporary spawning aggregations) is exponential: more prey energy per sea lion is necessary as the number of sea lions increases as

$E=10^{\frac{\log (N)-2.25}{0.59}}$,

where $\mathrm{E}$ is required prey energy for the number of sea lions, N. Using this formula an estimated $5.77 \mathrm{TJ}$ of prey energy would be required within $\sim 20 \mathrm{~km}$ of a haulout to temporarily attract and support 500 
Steller sea lions while $18.67 \mathrm{TJ}$ would be necessary to attract and support 1000 sea lions. Tollit et al. [22] found that approximately $25.8 \%$ of the composite mean bioenergetic diet contribution for W-SSL in the Aleutian Islands came from Gadus sp. (gadids, Pacific cod and pollock) and Sebastes sp. (rockfish, predominantly POP) in 2008 and 2012. Therefore the energy from these species required to sustain and attract a given number of sea lions would be

$E_{\text {gadidsandrockfish. }}=0.258\left(10 \frac{\log _{10}(\mathrm{~N})-2.25}{0.59}\right)$.

The prey energy from adult pollock [30] in March is $0.0041 \mathrm{TJ} \mathrm{t}^{-1}$ and for POP [31] is $0.0054 \mathrm{TJ} \mathrm{t}^{-1}$. Therefore for a given number of sea lions, with a $10 \%$ allowance for population growth, the biomass (B) of gadids and rockfish necessary would be

$B_{\text {gadidsand rockfish }}=\left(\frac{0.258}{0.0041 P_{\text {gadids }}+0.0054 P_{\text {rockfish }}}\right)\left(10 \frac{\log _{10}(1.1 N)-2.25}{0.59}\right)$,

where $\mathrm{P}_{\text {gadids }}$ and $\mathrm{P}_{\text {rockfish }}$ are the proportions of gadids and rockfish available as prey for the local W-SSL population. The LBC could then be calculated as the difference between the survey biomass and the W-SSL biomass requirements calculated here. The LBC would be rather conservative given the diverse sea lion diet results obtained from diet data collected during the 2008 study [21].

The population of W-SSL in the study area (between Tanaga and Atka islands) was estimated to be 4774 sea lions [32]. To sustain this population and allow for a $10 \%$ population growth there would need to be at least $80 \mathrm{TJ}$ of prey energy from gadids and rockfish in the area. The initial 2007 survey estimated pollock to comprise 91\% and POP 9\% of the mid-water and near-bottom biomass in the surveyed area. Using the biomass requirement formula from above, W-SSL in the study area would have required a combined biomass of pollock and POP of $18,994 \mathrm{t}$ to meet their needs. The initial 2007 survey estimated there to be $21,140 \mathrm{t}$, allowing for an LBC of $2146 \mathrm{t}$ or $10 \%$ of the overall biomass. In the initial 2008 survey, pollock comprised $78.4 \%$ and POP $21.6 \%$ of the mid-water and near-bottom biomass with a total biomass of 34,614 t. Again using the formula for W-SSL biomass requirements the total biomass required for W-SSL would have been $18,283 \mathrm{t}$, resulting in a maximum LBC of $16,330 \mathrm{t}$, or $47 \%$ of the total estimated biomass.

Selected portions of W-SSL critical habitat in the Aleutian Islands were reopened to directed pollock fishing in 2015, but there has essentially been no active fishery in the Aleutian Islands since 1998 and the W-SSL population continues to decline west of Tanaga Island $[33,34]$. Implementing an ecosystem-based fisheries management plan for an Adak-based late winter to early spring AI pollock fishery necessarily involves setting a catch level that makes it economically sensible for fishing companies to pursue and also accounts for the requirements of a recovering and recovered W-SSL population. As the technical feasibility of the proposed management system has been demonstrated, consultations between NMFS Protected Resources (ensuring recovery of the W-SSL), NMFS Sustainable Fisheries (supporting healthy and sustainable fisheries), and concerned stakeholders would be the next step in the process for setting acceptable bounds on W-SSL forage thresholds if this project were to move forward.

Substantial aggregations of pollock were observed in the region of interest $(38,000 \mathrm{t}$ in the final 2008 survey), however the relatively low abundance of pollock in comparison with other regions (e.g. eastern Bering Sea at between $10 \times 10^{9} \mathrm{t}$ and $15 \times 10^{9} \mathrm{t}$ [35]), high abundance of POP, substantial effort and risk required to fish in the rough weather conditions normal for this region and season, and the availability of more lucrative fisheries elsewhere (e.g. AI and eastern Bering Sea Pacific cod fisheries) have, since the completion of this project, resulted in little interest by fishing industry stakeholders in pursuing this fishery. It should be noted that the 2006-2007 AICASS demonstrated to the industry stakeholders that the AI pollock fishery was not as profitable as previously believed. This realization was a direct result of the cooperative research in which the fishing industry took part and demonstrates an added benefit of involving fishers directly in research in that the results of the cooperative research had direct and immediate local legitimacy [36]. Even when the technical and ecosystem challenges for this type of co-management system have been addressed, in the end its feasibility depends on the perception of the fishers and fish processors on whether this system, which imposes a larger portion of the management costs on the industry, remains cost effective and results in a profitable and sustainable fishery. Unless the population of AI pollock increases substantially, it is unlikely that the proposed type of management system will be implemented in this fishery.

\subsection{Wider implications and applications}

Although the cooperative management system proposed is not likely to be implemented in the AI, it was shown to be feasible. In effect the proposed model is an in-season management system based on escapement like those commonly implemented in salmon $[37,38]$ and herring [39] fisheries, except instead of limiting catch based on future recruitment goals the limits are determined by local forage requirements of other sensitive species. The innovation in the proposed system was the use of cooperative acoustic surveys to estimate local fish biomass levels and taking into account the forage needs of sensitive species. The requirement for this type of system is an interested fishing community with the appropriate acoustic systems and target species that are acoustically available (i.e. mid-water species with discernable acoustic signatures). Echosounders of high enough quality to conduct scientific surveys have been widely adopted by fishers and are ubiquitous in most developed fisheries [40-43]. Eastern Bering Sea pollock fisheries would also be a possible candidate for integrating cooperative acoustic surveys and local management to mitigate hypothesized competitive interactions with northern fur seals (Callorhinus ursinus) [43] that could be a factor in its continued population decline [44]. There has been considerable research on nutritional requirements for both Steller sea lions and northern fur seals [30,45-47] and the catch accounting system for bottom fish described for the Aleutian Islands [11] is similarly implemented in this fishery.

Globally there are several opportunities in developed fisheries where management systems based on surveys conducted by commercial fishing vessels could be implemented to manage impacts and interactions between marine mammals and fishers. The Celtic shelf and Irish Sea pelagic fisheries (e.g. Atlantic herring (Clupea harengus)) have been shown to overlap with gray seal (Halichoerus grypus) forage grounds [48] resulting in prey competition between the fishery and seals. Acoustic data are being collected from fishing vessels operating in this region [49]. A simple adaptation of the methods already employed to conduct formal cooperative surveys could provide an opportunity for local co-management of these fisheries to reduce negative interactions and fisheries impacts through competition. In the Southern Ocean Antarctic krill (Euphausiidae superba) fisheries [50], there is the potential for ecological impacts across a wide-range of taxa from invertebrates, fishes, marine birds, to marine mammals as Antarctic krill are forage for a great number of species, making this fishery a candidate for more intense local management [51]. Acoustics are used to conduct surveys of this stock under the Convention for the Conservation of Antarctic Marine Living Resources (CCAMLR) [52] and fishers employ similar acoustic systems for finding fishable aggregations [53]. The regions fished within the Southern Ocean are remote, large, and difficult to survey resulting in high costs for management and intermittent surveys. Relying on a cooperative monitoring model could potentially reduce costs while increasing the frequency of surveys in the regions of direct interest to fishers. A system such as proposed for the Aleutian Islands pollock fishery with co-monitoring and co-management components could potentially better manage local removals reducing potential local ecological impacts of this fishery. 
The co-monitoring and co-management system explored here for the AI pollock fishery could be adapted to other developing fisheries, particularly emerging Arctic fisheries on pelagic species. Given warming climate trends Arctic fisheries on polar cod (Boreogadus saida) may be expanded [54] in the Russian Arctic and, although currently protected [55], developed in the United States, Canadian, and central Arctic Ocean in the near future. Building a management model for gathering data on this keystone species prior to the beginning of large-scale harvesting is essential to avoid adversely impacting the many sensitive species of birds and marine mammals that require this species as an essential component of their summer diets [56]. This includes the ringed seal (Phoca hispida) which is protected under the MMPA with several sub-species declared endangered or threatened and is reliant on polar cod as an important component of its forage [57]. An expansion of the polar cod fishery would likely impact this protected species. Preemptively developing a co-management and co-monitoring system such as proposed for the AI pollock fishery for the polar cod fishery would allow a precautionary approach while spreading the costs of managing this distant fishery to those profiting from the fishery. Unlike the highly subsidized fisheries developed in the past, implementing a system similar to that we describe in this paper would help ensure fishing could only occur with adequate understanding of its ecological and economic impacts. In addition, such a system where co-monitoring and a deep understanding of the ecological impacts of the fishery is a required component of the management system, consultations with local indigenous communities would be well-informed, a national [58] and Arctic Council [59] priority.

\section{Acknowledgements}

The authors would like to thank the captain and crew of the FV Muir Milach for their hard work in completing this project, as well as the Aleut Corporation for coordinating among industry and government stakeholders to make this project possible. The authors would like to recognize Dave Fraser in particular for his extensive endeavors on this project, both for his efforts in survey development and stakeholder coordination in Adak. In addition, the authors would like to thank Jeremy Sterling and Susanne McDermott for providing early reviews of this manuscript. This project was partially funded through a grant by the North Pacific Research Board project 730.

\section{References}

[1] J.C. Nagle, Law's Environment: How the Law Shapes the Places We Live, Yale University Press, USA, 2010.

[2] NMFS, Recovery Plan for the Steller Sea Lion (Eumetopias jubatus). Revision. National Marine Fisheries Service, Silver Spring, MD, 2008, p. 325.

[3] L. Fritz, K. Sweeney, R. Towell, T. Gelatt, Aerial and Ship-based Surveys of Steller Sea Lions (Eumetopias jubatus) conducted in Alaska in June-July 2013 through 2015, and an Update on the Status and Trend of the Western Distinct Population Segment in Alaska, U.S. Dep. Commer., NOAA Tech. Memo, 2016, p. 72, http://dx. doi.org/10.7289/V5/TM-AFSC-321.

[4] S. Atkinson, D.P. Demaster, D.G. Calkins, Anthropogenic causes of the western Steller sea lion Eumetopias jubatus population decline and their threat to recovery, Mammal. Rev. 38 (2008) 1-18, http://dx.doi.org/10.1111/j.1365-2907.2008. 00128.x.

[5] National Research Council (NRC), Decline of the Steller Sea Lion in Alaskan Waters: Untangling Food Webs and Fishing Nets, National Academy of Sciences Press, Washington, DC, USA, 2003.

[6] L. Fritz K. Sweeney R. Towell T. Gelatt Aerial and ship-based surveys of Steller sea lions (Eumetopias jubatus) conducted in Alaska in June-July 2013 through 2015, and an update on the status and trend of the western distinct population segment in Alaska, 2016, p. $72\langle$ http://dx.doi.org/10.7289/V5/TM-AFSC-321〉.

[7] L.D. Rea, J.M. Castellini, L. Correa, B.S. Fadely, T.M. O'Hara, Maternal Steller sea lion diets elevate fetal mercury concentrations in an area of population decline, Sci. Total Environ. 454 (2013) 277-282, http://dx.doi.org/10.1016/j.scitotenv.2013. 02.095.

[8] S. Barbeaux, J. Ianelli, W. Palson, Assessment of the pollock stock in the Aleutian Islands for 2014. In: Stock assessment and fishery evaluation report for the groundfish resources of the Bering sea/Aleutian Islands regions, North Pac. Fish. Manag. Counc., Anchorage, Alsk. (2013) (Available), 〈https://www.afsc.noaa.gov/ REFM/Docs/2013/AIpollock.pdf .
[9] R. Felthoven, H. Geier, A. Haynie, D. Layton, D. Lew, A. Poole, R. Rowe, J. Sepez, C Seung, E. Springer, R. Waters. Economic status of the groundfish fisheries off Alaska, 2005. Edited by T. Hiatt. In: Stock Assessment and fishery evaluation report for the groundfish fisheries of the Gulf of Alaska and Bering Sea/Aleutian Islands Area. North Pac. Fish. Mgmt. Council, Anchorage, Alaska, 2007. Available: 〈https://www.afsc.noaa.gov/refm/docs/2006/economic.pdf〉.

[10] M.W. Dorn, W.A. Karp, V.G. Wespestad, J. Ianelli, Quinn II, T.J.. Using fishing vessels to collect acoustic data for scientific purposes: preliminary results from midwater trawlers in the eastern Bering Sea walleye pollock fishery. In ICES Symposium on Acoustics in Fisheries and Aquatic Ecology, Montpellier, France pp. 10-14.

[11] J. Simmonds, D. Maclennan, Fisheries Acoustics Theory and Practice, second edition, Blackwell Science Ltd, Oxford, UK, 2005.

[12] J. DiCosimo, R.D. Methot, O.A. Ormseth, Use of annual catch limits to avoid stock depletion in the Bering Sea and Aleutian Islands management area (Northeast Pacific), ICES J. Mar. Sci. 67 (9) (2010) 1861-1865, http://dx.doi.org/10.1093/ icesjms/fsq060.

[13] J. Cahalan, J. Mondaragon, K. Gasper, Catch Sampling and Estimation in the Federal Groundfish Fisheries off Alaska, U.S. Dep. Commer., NOAA Tech. Memo, 2010, p. 42.

[14] S. Barbeaux, D. Fraser, Aleutian Islands Cooperative acoustic survey study for 2006, U. S. Dep. Commer., NOAA Tech. Memo. NMFS-AFSC 198 (2009) 91 (Available), 〈http://www.afsc.noaa.gov/Publications/AFSC-TM/NOAA-TM-AFSC-198.pdf〉.

[15] Alaska Fisheries Science Center Observer Sampling Manual. Fisheries Monitoring and Analysis Division, North Pacific Groundfish Observer Program. AFSC, 7600 Sand Point Way N.E., Seattle, Washington, 98115, 2017. Available: 〈https://www. afsc.noaa.gov/FMA/Manual_pages/MANUAL_pdfs/manual2017.pdf $\rangle$.

[16] S.J. Barbeaux, D. Fraser, L.W. Fritz, E.A. Logerwell, Cooperative Multispecies Acoustic Surveys in the Aleutian Islands, U.S. Dep. Commer., NOAA Tech. Memo, 2017, p. 57, http://dx.doi.org/10.7289/V5/TM-AFSC-347.

[17] S.J. Barbeaux, S. Romain, E. Logerwell, D. Fraser, Aleutian Islands Cooperative Acoustic Survey Study, 2007, U.S. Dep. Commer. NOAA Tech. Memo, 2016, p. 35 http://dx.doi.org/10.7289/V5/TM-AFSC-319.

[18] P. Petitgas, Geostatistics for fish stock assessments: a review and an acoustic application, ICES J. Mar. Sci. J. Cons. 50 (3) (1993) 285-298, http://dx.doi.org/10. 1006/jmsc.1993.1031.

[19] P.D. Walline, Geostatistical simulations of eastern Bering Sea walleye pollock spatial distributions, to estimate sampling precision, ICES J. Mar. Sci. J. du Cons. 64 (3) (2007) 559-569, http://dx.doi.org/10.1093/icesjms/fs1045.

[20] D. Fraser, Pers. Commun. Adak Seafoods LLC, 2008.

[21] L. Logerwell, S.J. Barbeaux, L. Fritz. A cooperative pollock acoustic biomass survey for management of fisheries interactions with Steller sea lions in the Aleutian Islands. North Pacific Fisheries Research Board Final Report, 106p, 2009. Available: 〈http://doc.nprb.org/web/07_prjs/730\%20Revised\%20Final\%20Report.pdf〉.

[22] D.J. Tollit, L. Fritz, R. Joy, K. Miller, A. Schulze, J. Thomason, W. Walker, T. Zeppelin, T.S. Gelatt, Diet of endangered Steller sea lions in the Aleutian Islands: new insights from DNA detections and bio-energetic reconstructions, Can. J. Zool (2017) (ja).

[23] A. Winship, A. Trites, A. Rosen, A bioenergetic model for estimating food requirements of Steller sea lions Eumetopias jubatus in Alaska, USA, Mar. Ecol. Progr Ser. 229 (2002) 291-312, http://dx.doi.org/10.3354/meps229291.

[24] M.F. Sigler, J.N. Womble, J.J. Vollenweider, Availability to Steller sea lions (Eumetopias jubatus) of a seasonal prey resource: a pre-spawning aggregation of eulachon (Thaleichthys pacificus), Can. J. Fish. Aquat. Sci. 61 (2004) 1475-1484.

[25] D.A.S. Rosen, Steller sea lions (Eumetopias jubatus) and nutritional stress: evidence from captive studies, Mammal. Rev. 39 (4) (2009) 284-306, http://dx.doi.org/10. 1111/j.1365-2907.2009.00150.x.

[26] E.H. Sinclair, T.K. Zeppelin, Seasonal and spatial differences in diet in the western stock of Steller sea lions (Eumetopias jubatus), J. Mamma 82 (4) (2002) 973-990.

[27] E.H. Sinclair, D.S. Johnson, T.K. Zeppelin, T.S. Gelatt, Decadal variation in the diet of western stock Steller sea lions (Eumetopias jubatus). U.S. Dep. Commer, NOAA Tech. Memo. NMFS-AFSC 248 (2013) 67 (Available), 〈https://www.afsc.noaa.gov/ Publications/AFSC-TM/NOAA-TM-AFSC-248.pdf $>$.

[28] J.N. Womble, M.F. Willson, M.F. Sigler, B.P. Kelly, G.R. VanBlaricom, Distribution of Steller sea lions Eumetopias jubatus in relation to spring-spawning fish in SE Alaska, Mar. Ecol. -Progr. Ser. 294 (2005) 271-282, http://dx.doi.org/10.3354/ meps 294271.

[29] J. Womble, M. Sigler, Seasonal availability of abundant, energy-rich prey influences the abundance and diet of a marine predator, the Steller sea lion Eumetopia jubutus, Mar. Ecol. Progr. Ser. 325 (2006) 281-293, http://dx.doi.org/10.3354/ meps 325281.

[30] J.J. Vollenweider, R.A. Heintz, L. Schaufler, R. Bradshaw, Seasonal cycles in wholebody proximate composition and energy content of forage fish vary with water depth, Mar. Biol. 158 (2) (2011) 413-427, http://dx.doi.org/10.1007/s00227-0101569-3.

[31] M. Perez, Calorimetry measurements of energy value of some Alaskan fishers and squids. U.S. Dep. Commer, NOAA Tech. Memo. NMFS-AFSC 32 (1994) 32 (Available), 〈https://www.afsc.noaa.gov/publications/AFSC-TM/NOAA-TM-AFSC32.pdf $>$.

[32] D. Johnson NMFS-AFSC-MML, Pers. Commun., 17January 2017, Seattle WA.

[33] M.M. Muto, et al., Alaska marine mammal stock assessments, 2015, U. S. Dep. Commer., NOAA Tech. Memo. NMFS-AFSC 323 (2016) 300, http://dx.doi.org/10. 7289/V5/TM-AFSC-323 (Document available), 〈http://www.afsc.noaa.gov/ Publications/AFSC-TM/NOAA-TM-AFSC-323.pdf $\rangle$.

[34] L. Fritz, K. Sweeney, R. Towell, T. Gelatt, Aerial and ship-based surveys of Steller sea lions (Eumetopias jubatus) conducted in Alaska in June-July 2013 through 2015, 
and an update on the status and trend of the western distinct population segment in Alaska, U. S. Dep. Commer., NOAA Tech. Memo. NMFS-AFSC 321 (2016) 72, http://dx.doi.org/10.7289/V5/TM-AFSC-321.

[35] J.N. Ianelli, T. Honkalehto, S. Barbeaux, B. Fissel, S. Kotwicki, Assessment of the walleye pollock stock in the Eastern Bering Sea, Stock assessment and fishery evaluation report for the groundfish resources of the Bering Sea/Aleutian Islands regions for 2014. North Pacific Fishery Management Council, Anchorage, AK, (2016), pp. 51-156 (Available), 〈https://www.afsc.noaa.gov/REFM/Docs/2016/ EBSpollock.pdf $>$.

[36] E. Pinkerton, Summary and conclusions, in: C. Dyer, J.R. McGoodwin (Eds.), Folk Management in the World's Fisheries, University of Colorado Press, Niwot, 1994.

[37] S. Wright, Contemporary Pacific salmon fisheries management, N. Am. J. Fis. Manag. 1 (1) (1981) 29-40.

[38] J. McDonald, The stock concept and its application to British Columbia salmon fisheries, Can. J. Fish. Aquat. Sci. 38 (1981) 1657-1664, http://dx.doi.org/10. 1139/f81-214.

[39] R.L. Stephenson, K. Rodman, D.G. Aldous, D.E. Lane, An in-season approach to management under uncertainty: the case of the SW Nova Scotia herring fishery, ICES J. Mar. Sci. 56 (1999) 1005-1013.

[40] G. Melvin, Y. Li, L. Mayer, A. Clay, Commercial fishing vessels, automatic acoustic logging systems and 3D data visualization, ICES J. Mar. Sci. J. du Consei 59 (1) (2002) 179-189, http://dx.doi.org/10.1006/jmsc.2001.1124.

[41] R. O'Driscoll, G. Macaulay, Using fish-processing time to carry out acoustic surveys from commercial vessels, ICES J. Mar. Sci. 62 (2005) 295-305, http://dx.doi.org/ 10.1016/j.icesjms.2004.11.013.

[42] B. Karp, Collection of acoustic data from fishing vessels, ICES Coop. Res. Rep. 287 (2007) 83 (Available), 〈https://www.ices.dk/sites/pub/Publication\%20Reports/ Cooperative\%20Research\%20Report\%20(CRR)/crr287/CRR\%20287.pdf〉.

[43] S.M. Fässler, T. Brunel, S. Gastauer, D. Burggraaf, Acoustic data collected on pelagic fishing vessels throughout an annual cycle: operational framework, interpretation of observations, and future perspectives, Fish. Res. 178 (2016) 39-46, http://dx. doi.org/10.1016/j.fishres.2015.10.020.

[44] R. Towell, R. Ream, J. Bengtson, M. Williams, J. Sterling. 2016 northern fur seal pup production and adult male counts on ther Pribilof Islands, Alaska. Memorandum For: The Record Date: November29, 2016. Available: 〈https://www. afsc.noaa.gov/nmml/PDF/NFurSealPupMem2016_Final.pdf $>$.

[45] M. Sigler, et al., Steller sea lion foraging response to seasonal changes in prey availability, Mar. Ecol. Progr. Ser. 388 (2009) 243-261 (Available), 〈http://www. int-res.com/abstracts/meps/v388/p243-261/>.

[46] C.E. Kuhn, R.R. Ream, J.T. Sterling, J.R. Thomason, R.G. Towell, Spatial segregation and the influence of habitat on the foraging behavior of northern fur seals (Callorhinus ursinus), Can. J. Zool. 92 (10) (2014) 861-873, http://dx.doi.org/10. 1139/cjz-2014-0087.

[47] A.J.M. Dalton, D.A.S. Rosen, A.W. Trites, Resting metabolic rate and activity: key components of seasonal variation in daily energy expenditure for the northern fur seal (Callorhinus ursinus), Can. J. Zool. 93 (8) (2015) 635-644, http://dx.doi.org/ 10.1139/cjz-2014-0313.

[48] T. Jeanniard-du-Dot, A.W. Trites, J.P. Arnould, J.R. Speakman, C. Guinet, Activity-specific metabolic rates for diving, transiting, and resting at sea can be estimated from time-activity budgets in free-ranging marine mammals, Ecol. Evol. 7 (9) (2016) 2969-2976, http://dx.doi.org/10.1002/ece3.2546.

[49] M. Cronin, H. Gerritsen, D. Reid, M. Jessopp, Spatial overlap of grey seals and fisheries in Irish waters, ome new insights using telemetry technology and VMS, PloS One 11 (9) (2016) e0160564, http://dx.doi.org/10.1371/journal.pone. 0160564.

[50] S.L. Hill, A. Atkinson, C. Darby, S. Fielding, B.A. Krafft, O.R. Godo, J.L. Watkins, Is current management of the Antarctic krill fishery in the Atlantic sector of the Southern Ocean precautionary? CCAMLR Sci. 23 (2016) 31-51 (Available), 〈http:// nora.nerc.ac.uk/515398/1/Hill\%20et\%20al.pdf $>$.

[51] S. Nicol, J. Foster, S. Kawaguchi, The fishery for Antarctic krill-recent developments, Fish. Fish. 13 (1) (2012) 30-40, http://dx.doi.org/10.1111/j.1467-2979. 2011.00406.x.

[52] J.L. Watkins, R. Hewitt, M. Naganobu, V. Sushin, The CCAMLR 2000 Survey: a multinational, multi-ship biological oceanography survey of the Atlantic sector of the Southern Ocean, Deep-Sea Res. II 51 (2004) 1205-1213, http://dx.doi.org/10. 1016/j.dsr2.2004.06.010.

[53] Krill biology, ecology and fisheries, in: I. Everson (Ed.), Fish and Aquatic Resources Series, Blackwell Science, Oxford, 2000, p. 372.

[54] M. Pan, H.P. Huntington, A precautionary approach to fisheries in the Central Arctic Ocean: policy, science, and China, Mar. Policy 63 (2016) 153-157, http://dx.doi. org/10.1016/j.marpol.2015.10.015.

[55] NPFMC. Fisheries Management Plan for the Fish Resources of the Arctic Management Area. North Pacific Fishery Management Council, 605 W. 4th Ave, Suite 306, Anchorage, AK, 99501. USA, 2009. Available: 〈https://www.npfmc.org/ wp-content/PDFdocuments/fmp/Arctic/ArcticFMP.pdf $\rangle$.

[56] H. Hop, H. Gjøsæter, Polar cod (Boreogadus saida) and capelin (Mallotus villosus) as key species in marine food webs of the Arctic and the Barents Sea, Mar. Biol. Res. 9 (9) (2013) 878-894, http://dx.doi.org/10.1080/17451000.2013.775458.

[57] B.P. Kelly, J.L. Bengtson, P.L. Boveng, M.F. Cameron, S.P. Dahle, J.K. Jansen, E.A. Logerwell, J.E. Overland, C.L. Sabine, G.T. Waring, J.M. Wilder, Status review of the ringed seal (Phoca hispida). U.S. Dep. Commer, NOAA Tech. Memo. NMFSAFSC 212 (2010) 250 (Available), 〈http://www.nmfs.noaa.gov/pr/species/Status \%20Reviews/Ringed\%20seal\%202012_.pdf $\%$.

[58] E.T. Bloom, Establishment of the Arctic council, Am. J. Int. Law 93 (3) (1999) 712-722, http://dx.doi.org/10.2307/2555272.

[59] F. Berkes, J. Mathias, M. Kislalioglu, H. Fast, The Canadian Arctic and the Oceans Act: the development of participatory environmental research and management, Ocean Coast. Manag. 44 (7) (2001) 451-469, http://dx.doi.org/10.1016/S0964 5691(01)00060-6. 